\title{
Produção de mudas de Alpinia purpurata (Vieill.) Schum, cultivar Red Ginger, em diferentes substratos e estimulador de enraizamento ${ }^{(1)}$
}

\author{
MARIAAPARECIDA MOREIRA(2), FLÁVIO GABRIEL BIANCHINI(2), CÉLIA CRISTINA REIS CRUZ ${ }^{(3)}$, \\ FERNANDO MORAES DANTAS ${ }^{(3)}$, IGOR MACHADO DE SOUZA ${ }^{(3)}$
}

\begin{abstract}
RESUMO
Alpinia purpurata é uma planta ornamental bastante utilizada no paisagismo como flor de corte. A propagação desta ornamental se dá por divisão de rizomas, multiplicando-se, também, pelas numerosas mudas que surgem nas brácteas da inflorescência após o florescimento. O objetivo desse trabalho foi verificar qual o melhor tipo de substrato para o enraizamento de mudas de Alpinia purpurata cv Red Ginger, produzidas nas brácteas das inflorescências, e a necessidade de estimulador de enraizamento nesse processo. O experimento foi desenvolvido na casa de vegetação da Fundação Municipal do Trabalhado (Fundat), em Aracaju, Sergipe, Brasil. Os tratamentos consistiram na combinação de misturas de substratos com e sem aplicação de enraizador. Os substratos utilizados foram: solo (S), pó de coco (PC), solo e esterco (SE), solo e pó de coco (SPC) e esterco e pó de coco (PCE), nas proporções 1:1, e solo, esterco e pó de coco (SPCE), nas proporções 1:1:1. O enraizador utilizado foi na concentração de $600 \mathrm{ppm}$ de AIB na solução. O delineamento estatístico utilizado foi o inteiramente casualizado, com 4 repetições e 4 plantas por repetição. As avaliações foram feitas aos 30 dias após a instalação do experimento, quando foram avaliados matéria fresca e seca de raiz, número de brotações e comprimento de raiz. Os dados obtidos foram submetidos à análise de variância e as médias, comparadas pelo teste de Scott Knot a 5\% de significância. Os substratos SE, PCE, SPCE e SPC tiveram comportamento semelhante em relação ao número de brotações, sendo superiores aos substratos $\mathrm{S}$ e PC, apresentando uma média de 2,28; 2,42; 2,12 e 2,09 brotações respectivamente. Com relação à matéria fresca e seca de raiz, as mudas de alpínia tiveram melhor desempenho no substrato PC, tendo apresentado valores de 3314,12mg e 303,82mg, respectivamente. Para comprimento de raiz, não houve diferença significativa. Com os resultados obtidos, pode-se concluir que não é necessária a utilização de enraizador, e o pó de coco foi o melhor substrato para as características avaliadas. Para a brotação, é necessária a suplementação com composto orgânico.
\end{abstract}

Palavras-chave: alpínia, enraizador, propagação.

\author{
ABSTRACT \\ Different substrates and rooting stimulation for seedling production of \\ Alpinia purpurata (Vieill.) Schum cultivar Red Ginger
}

\begin{abstract}
Alpinia purpurata is used extensively in landscaping and the demand, as cut flower, is increasing. The ornamental propagation gives, by rhizomes, many seedlings of inflorescence bracts after flowering. The purpose of this work was to verify the best substrate for rooting seedling of Alpinia purpurata produced in the inflorescences bracts and the need to use the root stimulation in the process. The experiment was carried out in Fundação Municipal of Trabalho (FUNDAT) in the Aracaju (SE), Brazil. The treatments consisted of the combination of mixtures of substrates with and without root stimulation. The substrates used were: soil; coconut dust; soil and coconut dust; coconut dust and bovine manure; soil and bovine manure; coconut dust, bovine manure and soil. The rooting stimulation used was a solution with a concentration of $600 \mathrm{ppm}$ of AIB. The experimental delineation was randomized, with four repetitions and using four plants per parcel each time. The evaluations were made 30 days after the installation of the experiment and evaluated: fresh and dry matter, root number and length and the number of shoots. The data obtained was submitted for analysis of variance and a medium compared Scott Knott test at the level of 5\% significance was carried out. The substrates SE, PCE, SPCE and SPC behaved the same in relation to the number of shoots, being above the substrates and S and PC, obtaining 2.28; 2,42; $2,092.12$ shoots, respectively. With regard to the root fresh and dry matter, seedlings performed the best in the substrate PC with $3314,12 \mathrm{mg}$ and $303,82 \mathrm{mg}$, respectively. There was no significant difference regarding root length. It can be concluded that the use of rooting powder is not required. Also coconut dust was the best subtract for the variables evaluated. The use of organic compost is required for the production shoot's.
\end{abstract}

Keywords: alpinia, rooting stimulation, propagation.

\section{INTRODUÇÃO}

A produção e a comercialização de flores e plantas ornamentais no Brasil começaram em escala comercial na década de $30 \mathrm{com}$ os imigrantes portugueses. Na década de 70 , entraram neste mercado os imigrantes japoneses e finalmente os imigrantes holandeses, que no início da década de 70 deram um impulso maior à comercialização, implantando um sistema de distribuição pelo país inteiro.

A floricultura brasileira começou a se destacar como atividade agrícola de importância econômica há mais de vinte anos, mas foi nos últimos dez anos que se verificou um crescimento significativo da oferta de alguns produtos da floricultura e do paisagismo. Isto ocorreu pela opção de produtores, situados próximos de importantes centros de consumo, entrarem nesta atividade na busca de uma

\footnotetext{
(1) Recebido em 29/08/2009 e aceito para publicação em 08/09/2011.

(2) Eng. Agrônomo, Profa. Departamento Eng. Agronômica/DEA/UFS: hij47@hotmail.com

(3) Eng. Agrônomos, Departamento Eng. Agronômica/DEA/UFS:fgbianchini@yahoo.com.br, igor_macso@hotmail.com
} 
alternativa rentável para suas pequenas propriedades rurais e pelo desenvolvimento de pesquisas próprias e incremento à produção, estando a floricultura se tornando uma nova realidade econômica (BONGERS, 2000).

Entre as plantas ornamentais, as tropicais são as que mais despertam o interesse dos produtores, principalmente pela durabilidade das suas flores aliada à sua beleza, gerando uma boa aceitação no mercado. O Nordeste vem se destacando com um crescimento significativo no cultivo de flores tropicais. Os Estados de Pernambuco, Alagoas e Ceará, principalmente, destacam-se como os maiores produtores/exportadores dessas espécies. O interesse por essas flores se dá por diversas características que favorecem sua comercialização, tais como beleza, exotismo, cores e formas diversas, resistência ao transporte, durabilidade póscolheita, além de grande aceitação no mercado externo, em especial nos países desenvolvidos (LOGES et al., 2005). As helicônias e as plantas da família Zingiberaceae são as de maior destaque, sendo as mais plantadas o bastãodo-imperador (Etlingera elatior), a alpínia (Alpinia purpurata) e o xampu (Zingiber spectabile Griff) (LOPES e BARBOSA, 1999).

A Alpinia purpurata (Vieill.) Schum é uma planta tropical pertencente à família Zingiberaceae, conhecida comumente como panamá. Trata-se de uma planta ornamental bastante utilizada no paisagismo de parques e residências face a uma intermitente florada durante todo o ano. É uma planta tropical perene, cuja temperatura ótima para produção está entre $24-30^{\circ} \mathrm{C}$, devendo a umidade relativa do ar oscilar entre 60 a $80 \%$, de crescimento vigoroso, formando touceiras espessas, tem odor característico que se assemelha ao gengibre (LAMAS, 2004).

É uma herbácea rizomatosa, ereta, florífera, originária das Ilhas dos Mares do Sul, de 1,5 - 2,0 m de altura, com hastes numerosas, densas, semelhantes à cana, de folhas verde-escuras espessas. Suas inflorescências são terminais, espigadas, com numerosas flores brancas, pequenas, com brácteas em forma de barco, vermelhas e vistosas.

Ocorre uma variedade de brácteas cor-de-rosa (LORENZI e SOUZA, 2001) e, devido à hibridação, podem aparecer tons que variam entre o vermelho e o rosa, até tonalidades mais esbranquiçadas. As variedades mais cultivadas no Brasil são Red Ginger (vermelha), Pink Ginger (rosa), Jungle King (vermelha), Jungle Queen (rosa) e Eileen MacDonald (rosa) (LORENZI e SOUZA, 2001; LAMAS, 2004).

A alpínia desenvolve-se bem em condições de meia sombra, podendo, também, ser cultivada a pleno sol (LAMAS, 2004), sendo muito sensível ao frio.

Em plantas ornamentais, como nas demais espécies vegetais, a qualidade da muda para produção comercial ou uma composição paisagística é de grande importância para que se alcancem os objetivos almejados. A produção de uma boa muda depende da qualidade das matrizes e das técnicas de propagação utilizadas. Muitas plantas ornamentais podem ser propagadas de maneira assexuada, o que implica a manutenção das características da variedade desejada e obtenção antecipada de produção. Esse processo depende de cuidados especiais com as plantas que servirão de matrizes para multiplicação da espécie. As matrizes devem ser mantidas sob rigoroso controle fitossanitário, visando ao máximo de qualidade das mudas que serão geradas a partir destas plantas. A aquisição de plantas matrizes deve ser criteriosa, não anexando à coleção novas plantas, sem antes proceder a uma quarentena, na observância quanto ao estado geral da nova planta (KAMPF, 2000).

A alpínia multiplica-se, facilmente, por divisão de rizomas e pelas numerosas mudas que surgem nas brácteas da inflorescência após o florescimento (LORENZI e SOUZA, 2001).

Deve-se dar preferência a rizomas provenientes de cultivos com mais de três anos de idade, com diâmetro acima de $2 \mathrm{~cm}$ e elevado peso. Plantas obtidas por este método, provenientes de matrizes maduras com pelo menos três anos de cultivo, produzirão mais precocemente, entrando em produção comercial aos 12 - 15 meses de idade (LAMAS, 2004).

O uso de substratos está relacionado, em geral, com o cultivo em recipientes, seja em sacos plásticos, latas, vasos ou bandejas. Em comparação com o cultivo a campo, onde as plantas dispõem de um volume ilimitado para o crescimento de suas raízes, no cultivo em recipientes, esse volume é muito reduzido (KÄMPF e FERMINO, 2000). Desta maneira, a escolha do substrato é uma das decisões mais importantes para produtores de mudas, devendo ser escolhidos substratos que apresentem boas características químicas, físicas, biológicas e de mercado.

Os substratos podem ser formados de materiais de origem mineral ou orgânica, combinando dois ou mais componentes, e o bom substrato é aquele que proporciona retenção de água suficiente para a germinação, além de permitir a emergência das plântulas, apresentando-se livre de organismos saprófitos. Ele deve garantir, por meio de sua fase sólida, a manutenção mecânica do sistema radicular e a estabilidade da planta; da fase líquida, o suprimento de água e nutrientes; e da fase gasosa, o suprimento de oxigênio e o transporte de dióxido de carbono entre as raízes e o ar externo (LAMAIRE, 1995).

Várias matérias-primas são consagradas no uso em misturas para compor substratos para plantas, como a casca de arroz (in natura, carbonizada ou queimada), poliestireno expandido, espuma fenólica, areia, subprodutos da madeira, como serragem e maravalha, fibra de madeira, compostos de lixo domiciliar urbano, compostos de restos de poda, solo mineral, xaxim e vermicomposto (KÄMPF, 2000).

A utilização de resíduos da agroindústria disponíveis regionalmente como componente para substratos pode propiciar redução de custos, assim como auxiliar na minimização da poluição decorrente do acúmulo desses materiais no meio ambiente (FERMINO, 1996).

Existem substratos comerciais de boa qualidade utilizados para a produção de mudas, no entanto, o custo pode ser elevado. Uma medida adequada consiste em utilizar substratos regionais que possam ser obtidos facilmente (SILVEIRA et al., 2002). Um exemplo é o pó de coco, que tem facilidade de produção, baixo custo e alta disponibilidade, vantagens adicionais apresentadas por este tipo de substrato.

O pó de coco apresenta excelentes qualidades físicas e químicas quando usado como substrato, tais como alta retenção de umidade, resistência à degradação, 
uniformidade, ser livre de patógenos e ervas daninhas. No entanto, sua alta relação $\mathrm{C} / \mathrm{N}$ pode provocar uma deficiência de nitrogênio na produção de mudas (ARENAS et al., 2002). Para corrigir a carência de nutrientes nos substratos, podese usar a suplementação de nutrientes (BEZERRA, 2003), com adubação ou uso de solução nutritiva (CAÑIZARES et al., 2002). Pode ser utilizado em substituição à vermiculita e, devido às suas propriedades de retenção de umidade, aeração e estimulador de enraizamento, é um excelente material orgânico para formulação de substratos (NUNES, 2000).

Para uso como substrato, a casca de coco passa por diversas operações, como corte, desfibramento, secagem, trituração, lavagem e, quando necessária, pela compostagem (CARRIJO et al., 2002). Da indústria de processamento de coco verde ou maduro, origina-se uma quantidade significativa de resíduos, sendo a casca de coco maduro geralmente a mais utilizada como combustível de caldeiras ou processada para beneficiamento de fibras longas, curtas ou pó.

$\mathrm{Na}$ composição do substrato, a fonte orgânica é responsável pela retenção de umidade e fornecimento de parte dos nutrientes para o crescimento de plântulas. Tradicionalmente, o esterco bovino é utilizado como fonte orgânica na composição de substratos para produção de mudas das mais diversas espécies, desde hortícolas até arbóreas (PAIVA SOBRINHO et al., 2010).

Em busca de acelerar o processo de enraizamento de mudas e, consequentemente, o processo de produção, fitorreguladores são comumente empregados. Os mais utilizados são AIB (ácido indolbutírico), ANA (ácido naftalenacético), $\mathrm{GA}_{3}$ (ácido giberélico), citocinina, etileno, nitrato de potássio, a tioureia, entre outros (LAMAS, 2004). São compostos de grande importância na propagação de espécies ornamentais, podendo ser aplicados externamente, via líquida ou sólida (LOPES e BARBOSA, 1999). Além de serem utilizados de forma pura, o que é mais comum, podem ser encontrados comercialmente em formulações com macro e micronutrientes.

O objetivo desse trabalho foi verificar a possibilidade do uso do pó de coco como componente de substrato para produção de mudas de Alpinia purpurata e a necessidade do uso de estimulador de enraizamento.

\section{MATERIAL E MÉTODOS}

O experimento foi realizado na casa de vegetação da Fundação Municipal do trabalho (FUNDAT), órgão pertencente à Prefeitura Municipal de Aracaju, situado no município de Aracaju/SE, no período de janeiro a fevereiro de 2008. A casa de vegetação utilizada apresenta cobertura superior com plástico transparente, laterais com tela antiafídica e sombrite na parte superior para diminuir temperatura.

O delineamento utilizado foi o inteiramente casualizado, em esquema fatorial $6 \times 2$, com 4 repetições utilizando 4 plantas por repetição. O primeiro fator foram os substratos solo (S), pó de coco (PC), solo e esterco (SE), solo e pó de coco (SPC), esterco e pó de coco (PCE), nas proporções $1: 1$, e solo, esterco e pó de coco (SPCE), nas proporções 1:1:1; e o segundo fator foi presença e ausência do estimulador de enraizamento.
Foi utilizado estimulador de enraizamento comercial, contendo 600ppm de ácido indolbutírico (AIB) e, também, enxofre, boro, cloro, ferro e zinco.

As mudas de alpínia utilizadas no ensaio foram oriundas da parte aérea da planta, surgidas nas brácteas da inflorescência após o florescimento. Para a obtenção das mudas em quantidade suficiente para o ensaio, foi necessário fazer poda do ápice das inflorescências a fim de acelerar o processo de desenvolvimento dos propágulos. Os propágulos foram coletados no final da tarde e plantadas logo em seguida para evitar a desidratação.

As mudas foram mergulhadas na solução contendo 600ppm de AIB, durante 45 minutos antes do plantio.

O solo utilizado foi do tipo franco arenoso, de baixa fertilidade, coletado no Campus Rural da Universidade Federal de Sergipe; o pó de coco e esterco foram obtidos no comércio local. A análise do solo mostrou o seguinte resultado: Matéria orgânica $=11,8 \mathrm{~g} / \mathrm{dm}^{3}$; cálcio + magnésio $=1,36 \mathrm{cmolc} / \mathrm{dm}^{3} ;$ cálcio $=0,85 \mathrm{cmolc} / \mathrm{dm}^{3}$; magnésio $=0,51 \mathrm{cmolc} / \mathrm{dm}^{3} ;$ alumínio $=0,31 \mathrm{cmolc} / \mathrm{dm}^{3}$; sódio $=0,051 \mathrm{cmolc} / \mathrm{dm}^{3} ;$ potássio $=0,07 \mathrm{cmolc} / \mathrm{dm}^{3}$; hidrogênio $=$ alumínio $=2,23 \mathrm{cmolc} / \mathrm{dm}^{3} ;$ sódio $=11,8 \mathrm{ppm}$; potássio $=27,1 \mathrm{ppm} ;$ fósforo $=0,80 \mathrm{ppm}$; saturação de bases $=39,9 \%$; e pH em água $=5,4$

A preparação dos substratos foi feita manualmente, em seguida foram distribuídos em bandejas de isopor, com 72 células.

Os substratos foram molhados para facilitar o plantio das mudas, sendo colocada uma muda com três folhas em cada célula. As mudas oriundas dessas brotações foram selecionadas de acordo com o tamanho e o número de folhas.

O fornecimento de água foi feito nos primeiros quatro dias pela manhã e ao final da tarde, para evitar desidratação das folhas, com regador de crivo fino. Após o quarto dia, o fornecimento de água foi feito apenas no período da manhã.

Aos 30 dias após o plantio, foram avaliadas as seguintes características:

- Comprimento das raízes: as mudas foram retiradas da bandeja com os respectivos substratos e lavadas para retirar o substrato aderido às raízes. Em seguida, foi medido o comprimento do sistema radicular das mudas, porção abaixo do nó radicular, até a raiz de maior comprimento, com o auxílio de uma régua milimetrada, computando-se os resultados médios de cada tratamento em centímetro.

- Número de brotações: após medição do sistema radicular, avaliou-se o número de brotações emergidas de cada muda, expressando-se os resultados pelo número médio de brotações de cada tratamento.

- Matéria fresca e matéria seca das raízes (MF e MS): as raízes destacadas das mudas foram pesadas em balança analítica para determinar a matéria fresca. Após esse procedimento, foram acondicionadas em sacos de papel, por tratamento, e colocadas para secar a $55^{\circ} \mathrm{C}$ até atingirem peso constante para determinação da matéria seca. Quando retiradas da estufa e resfriadas, foram pesadas, obtendo-se o peso de matéria seca. Os resultados foram expressos em miligramas.

Os dados obtidos foram submetidos à análise de variância e as médias comparadas pelo teste de Scott Knott ao nível de 5\% de significância. 


\section{RESULTADOS E DISCUSSÃO}

Pelos resultados da análise de variância, verificou-se que houve diferença significativa a $5 \%$ de probabilidade somente para o fator substrato em todas as variáveis analisadas, com exceção para o comprimento de raiz, em que não houve significância para os fatores estudados.

$\mathrm{O}$ uso do estimulador de enraizamento não mostrou diferenças significativas em relação aos tratamentos.

Analisando o fator substrato, observou-se que com relação ao comprimento da raiz (Tabela 1) não houve diferença significativa nos diferentes tratamentos. Em todos os substratos, a raiz atingiu o comprimento total da célula da bandeja, o que pode ser explicado pela presença de necrose no ápice das raízes que atingiram o fundo das bandejas, decorrentes do processo chamado poda pelo ar.

Para número de brotações, os substratos SE, PCE, SPCE e SPC tiveram o mesmo comportamento, sendo superiores aos substratos S e PC, apresentando uma média de 2,28; 2,42; 2,12 e 2,09 brotações, respectivamente. Essa variável é importante, pois na produção de mudas, ocorrer brotação antes do enraizamento não é desejável (FACHINELLO et al., 2005), visto que as reservas do material propagativo devem ser utilizadas para enraizamento e não para brotações.

Com relação à matéria fresca de raiz, as mudas de alpínia tiveram melhor desempenho no substrato PC, seguido pelos substratos S e SPC (Tabela 2). Os piores resultados foram obtidos com substratos aos quais se adicionou esterco. Tanto o solo, como o pó de coco quando misturados com esterco proporcionaram uma redução na produção de matéria fresca de raiz. Esse fato pode confirmar a ausência de nutrientes no pó de coco, pois substrato feito a partir das fibras de coco não tem os nutrientes essenciais para as plantas (CARRIJO et al., 2002), e a falta de nutriente no substrato obriga a raiz a uma maior exploração do substrato, afetando crescimento, morfologia e distribuição do sistema radicular no substrato. Segundo MARSCHENER (1995), em condições ótimas de suprimento de nutriente, principalmente de nitrogênio, as raízes se tornam mais ramificadas e superficiais.

Além disso, o pó de coco apresenta propriedades de retenção de umidade, aeração e estimulador de enraizamento (NUNES, 2000). Essas características proporcionaram menos estresse às mudas nos primeiros dias do plantio, permitindo um melhor desempenho delas.

Quanto à matéria seca (Tabela 2), destacaram-se o solo e o pó de coco, estatisticamente iguais. Observou-se que os substratos que tiveram o melhor desempenho quanto à matéria fresca e seca foram os que tiveram pior desempenho no número de brotações. A explicação se deve ao fato de que tanto o pó de coco como o solo coletado no Campus Rural são substratos pobres em nutrientes e as mudas desses substratos dispunham somente das suas reservas, então, a prioridade era emitir raízes para em seguida emitir as brotações. Os demais substratos, especialmente os que continham esterco, emitiram mais brotações, pois, além das reservas das mudas, tinham nutrientes à disposição.

O pó de coco mostrou-se ótimo componente para a composição de substratos na produção de mudas de alpínia, e é importante que se obtenham componentes na região evitando o aumento do custo das mudas. Em Sergipe, o pó de coco é de fácil obtenção, visto ser um resíduo da indústria de fibra, necessitando apenas de uma lavagem para retirada do excesso de sais (NUNES, 1999).

\section{CONCLUSÕES}

Com base nos resultados obtidos e considerando as condições em que o trabalho foi conduzido, o pó de coco foi o melhor substrato para as características de raiz de Alpinia purpurata (Vieill.) Schum, cultivar Red ginger.

Para número de brotações, concluiu-se que é necessária a suplementação com adubação orgânica.

\section{REFERÊNCIAS}

ARENAS, M., VAVRINA, C.S., CURNELL. J.A., HANLON, E.A. E HOCHMUTH, G.J.. Coir as an Alternative to peat in media for tomato transplants production. HortScience, Alexandria, v. 37, n. 2, p. 300$312,2002$.

BEZERRA, F.C. Produção de mudas de hortaliças em ambiente protegido. Fortaleza: Embrapa Agroindústria Tropical. 2003, 22p. (Documentos, 72).

BONGERS, F .J. G. Informativo IBRAFLOR. Holambra, p. $1-10.2000$

CAÑIZARES, K.A.; COSTA, P.C.; GOTO.; VIEIRA, A.R.M.. Desenvolvimento de mudas de pepino em diferentes substratos com e sem uso de solução nutritiva. Horticultura Brasileira, Brasília, v.20, n.2, p.227-229. 2002

CARRIJO, O. A.; LIZ, R. S. de.; MAKISHIMA, N. Fibra de casca de coco verde como substrato agrícola. Horticultura Brasileira, Brasília, v.20, n.4, p.533-535, 2002.

FACHINELLO, J.C.; HOFFMANN, A.; NACHTIGAL, J.C. Propagação de plantas frutíferas. Brasília-DF: Embrapa Informação Tecnológica. 221p. 2005.

FERMINO, M.H. Aproveitamento de resíduos industriais e agrícolas como alternativas de substratos hortícolas. 1996. 90f. Dissertação (Mestrado em fitotecnia) - Programa de Pós-Graduação em Agronomia. Faculdade de Agronomia, Universidade Federal do Rio Grande do Sul, Porto Alegre, 1996.

KÄMPF, A.N. Substrato. In: KÄMPF, A.N. (Coord). Produção comercial de plantas ornamentais. Guaíba: Agropecuária, 2000. 254p.

KÄMPF, A.N. Seleção de materiais para uso como substrato. In: KÄMPF, A.N.; FERMINO, M.H. Substratos para plantas: a base da produção vegetal em recipientes. Porto Alegre: Genesis, 2000, p. 209-215.

LAMAS, A. M. - Curso - Floricultura Tropical-Técnicas de cultivo. 2004, publicação Sebrae - série Agronegócios. 
LAMAIRE, F. Physical, chemical and biological properties of growing medium. Acta Horticulturae, Kyoto, v. 396, p. 273-284, 1995.

LOGES, V.; TEIXEIRA, M. C. F.; CASTRO, A. C. R.; COSTA, A. S. Colheita, pós-colheita e embalagem de flores tropicais em Pernambuco. Horticultura Brasileira, Brasília, DF, v. 23, n. 3, p. 699- 702, 2005.

LOPES, L.C.; BARBOSA, J.G. Propagação de Plantas Ornamentais - Boletim de Extensão n⿳ 267, Viçosa- MG, UFV, 1999.

LORENZI, H.; SOUZA, H.M. Plantas Ornamentais no Brasil - arbustivas, herbáceas e trepadeiras. 3a. edição. Nova Odessa - SP: Instituto Plantarum. 2001,1120 pp.

MARSCHENER, H. Mineral nutrition of higher plants. 2 ed. London: Academic Press. 889p. 1995.
NUNES, M.U.C. Recomendações Técnicas para o cultivo do tomate (Lycopersicon esculentum Mill) em Sergipe. Aracaju: Embrapa Tabuleiros Costeiros, 1999. 31p. (Circular Técnica, 14)

NUNES, M.U.C. Produção de mudas de hortaliças com o uso da plasticultura e do pó de coco. Aracaju: Embrapa Tabuleiros Costeiros, 2000. 29p. (Embrapa Tabuleiros Costeiros. Circular técnica).

PAIVA SOBRINHO S.; LUZ, P. B. da.; SILVEIRA, T. L. S.; RAMOS, D. T.; NEVES, L. G.; BARELLI, M. A. A. Substratos na produção de mudas de três espécies arbóreas do cerrado. Revista Brasileira Ciências Agrárias. Recife, v.5, n.2, p.238-243, 2010.

SILVEIRA, E. B. et al. Pó de coco como substrato para produção de mudas de tomateiro. Horticultura Brasileira. Brasília, v. 20, n. 2, p. 211-216, 2002.

Tabela 1. Número de brotações e comprimento de raiz de mudas de Alpinia purpurata em função de substratos Table 1. Number of shoots and root length of seedlings of Alpinia purpurata depending on substrate

\begin{tabular}{lcc}
\hline Substratos & Número de brotações & Comprimento de raiz \\
\hline SE & $2,28 \mathrm{~A}$ & $9,26 \mathrm{~A}$ \\
PCE & $2,42 \mathrm{~A}$ & $9,46 \mathrm{~A}$ \\
SPCE & $2,12 \mathrm{~A}$ & $9,74 \mathrm{~A}$ \\
SPC & $2,09 \mathrm{~A}$ & $9,94 \mathrm{~A}$ \\
S & $1,64 \mathrm{~B}$ & $10,23 \mathrm{~A}$ \\
PC & $1,58 \mathrm{~B}$ & $10,81 \mathrm{~A}$ \\
\hline
\end{tabular}

$\mathrm{SE}=$ solo+esterco, $\mathrm{PCE}=$ pó de coco+esterco, $\mathrm{SPCE}=$ solo+pó de coco+esterco, $\mathrm{SPC}=$ solo+pó de coco, $\mathrm{S}=$ solo, $\mathrm{PC}=$ pó de coco

Tabela 2. Matéria fresca e seca de raiz (mg) de Alpinia purpurata em função de diferentes substratos Table 2. Fresh and dry root $(\mathrm{mg})$ of Alpinia purpurata for different substrates

\begin{tabular}{lcc}
\hline Substratos & Matéria fresca $(\mathrm{mg})$ & Matéria seca $(\mathrm{mg})$ \\
\hline SE & $624,80 \mathrm{C}$ & $198,39 \mathrm{~B}$ \\
PCE & $856,70 \mathrm{C}$ & $122,72 \mathrm{~B}$ \\
SPCE & $933,19 \mathrm{C}$ & $268,52 \mathrm{~A}$ \\
SPC & $1269,45 \mathrm{~B}$ & $228,29 \mathrm{~B}$ \\
S & $1424,55 \mathrm{~B}$ & $434,62 \mathrm{~A}$ \\
PC & $3314,12 \mathrm{~A}$ & $303,82 \mathrm{~A}$ \\
\hline
\end{tabular}

$\mathrm{SE}=$ solo+esterco, $\mathrm{PCE}=$ pó de coco+esterco, $\mathrm{SPCE}=$ solo+pó de coco+esterco, $\mathrm{SPC}=$ solo+pó de coco, $\mathrm{S}=$ solo, $\mathrm{PC}=$ pó de coco 